\section{Fenol (CAS 108-95-2)}

por Pedro Henrique Ramos de Oliveira

(1) fenol, também conhecido como ácido carbólico, ácido fênico ou ainda hidroxibenzeno é uma substância orgânica que se apresenta como um sólido cristalino, volátil, de odor característico e de formula molecular $\mathrm{C}_{6} \mathrm{H}_{6} \mathrm{O}$. É toxico, levemente ácido e solúvel em água de forma moderada (8,3g em $100 \mathrm{ml})$, tem peso molecular de 94,1g. $\mathrm{mol}^{-1}$, ponto de fusão de $43^{\circ} \mathrm{C}$, ponto de ebulição $182^{\circ} \mathrm{C}$, densidade relativa $1,071 \mathrm{~g} \cdot \mathrm{ml}^{-}$ ${ }^{1}$ a $20{ }^{\circ} \mathrm{C}$, pKa $=9,95 \mathrm{em}$ água. É solúvel em benzeno, etanol, clorofórmio, éter etílico, glicerol, dissulfito de carbono e em bases como o hidróxido de sódio. ${ }^{1}$ Foi descoberto em 1834 pelo químico Friedlieb Ferdinand Runge no fracionamento do alcatrão da hulha, umas das principais formas de obtenção do fenol. ${ }^{2}$

O Fenol possui um caráter ácido fraco, ainda mais quando comparado a álcoois alifáticos. Isso se dá pela maior estabilidade de sua base conjugada, que ocorre devido à deslocalização do par de elétrons não ligante do oxigênio através do sistema no anel benzênico (Esquema 1). Convém destacar que a força do ácido varia de acordo com os substituintes ligados ao anel benzênico. ${ }^{3}$

Em álcoois conjugados nota-se a presença do equilíbrio ceto-enólico, entretanto no fenol tal equilíbrio é intensamente deslocado para a fração enólica. Isso ocorre devido à diminuição da energia de ressonância, a qual a molécula precisaria para formar o tautômero ceto, sendo esta condição extremamente desfavorável conferindo instabilidade ao fenol (Esquema 2). ${ }^{4}$

\section{Síntese industrial do} Fenol

Ao longo dos anos, diversas metodologias foram desenvolvidas para a síntese industrial do fenol. As principais rotas sintéticas compreendem, a oxidação
Data de publicação na Web: 12 de abril de 2015 Recebido em 5 de novembro de 2014 Aceito para publicação 11 de abril de 2015

do cumeno e a oxidação do tolueno. No início do Século $X X$, o fenol era produzido majoritariamente por técnicas que envolviam a cloração ou a sulfonilação do benzeno, o que era sustentado pela demanda da indústria de resinas fenólicas logo após a primeira guerra mundial. A partir da metade dos anos 40 até a metade dos anos 60, a rota de oxidação do Cumeno (ou processo de Hock como também é conhecido) passou a ser implantada para a produção em larga escala. Já nos anos 90 , mais de $90 \%$ do fenol produzido era sintetizado industrialmente utilizando-se esta rota. ${ }^{2,5}$

Uma das características dessa rota é a obtenção de coprodutos como $0 \alpha$ metilestireno e a acetona. No Brasil, o Fenol é produzido pela oxidação do cumeno, sendo a multinacional Francesa Rhodia a principal empresa responsável pela sua obtenção - possui uma fábrica ampliada em 2009 para a produção exclusiva do fenol localizada na cidade de Paulínia/SP. ${ }^{7} \quad$ A empresa 


\section{Reagentes Químicos}

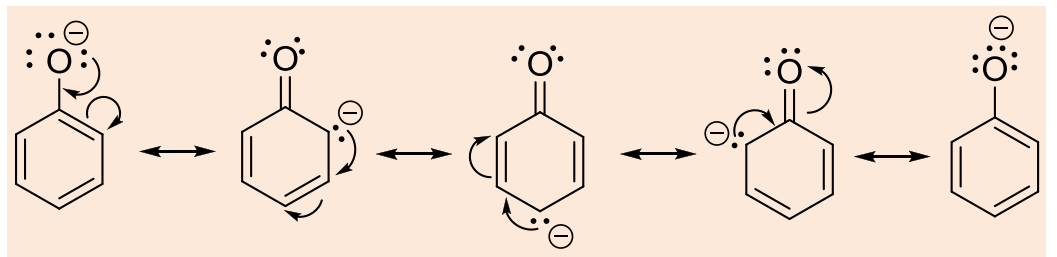

Esquema 1. Estruturas de ressonância do íon fenóxido<smiles>O=C1C=CCC=C1</smiles>

Esquema 2. Tautomerismo ceto-enólico

também produz derivados do fenol como nylon, resinas fenólicas variadas, bisfenol e difenóis resultantes da oxidação controlada do fenol, sendo a empresa líder nesse segmento no país. ${ }^{6,7}$

A nível global a multinacional INEOS é a maior produtora de fenol e seus derivados tendo movimentado em 2008 cerca de 3,3 bilhões de euros relativos a produção de fenol, acetona, cumeno, $\alpha$-metilestireno acetofenona. ${ }^{8}$

Síntese do Fenol via Oxidação do Cumeno

A rota sintética baseada na oxidação do cumeno vem sendo a mais empregada nos últimos anos, sendo que em 2008, mais de $97 \%$ do fenol em todo o mundo foi produzido desta forma. A oxidação do cumeno foi inicialmente proposta por Hock e Lang em 1944 (Esquema 3). Após a Segunda Guerra Mundial o processo industrial de obtenção do fenol via cumeno, foi desenvolvida em escala comercial pelas empresas The Distillers Co. no Reino Unido e pela Hercules Powder Company nos Estados Unidos. ${ }^{11}$

Apesar de o processo usar os princípios da síntese de Hock há diferenças no design e funcionamento das unidades de reação e destiladores na síntese do fenol de um fabricante para outro. $^{5}$

O Esquema 4 demonstra a planta industrial para a síntese do fenol. Incialmente o cumeno é oxidado pelo ar em hidroperóxido de cumeno (CHP), o cumeno é misturado em uma coluna com bolhas de ar que são introduzidas pela parte inferior do reator. A reação ocorre em fase liquida e ocorre por um complexo mecanismo radicalar sendo auto catalisada pelo CHP. As colunas de bolhas operam em pressões que variam da pressão atmosférica ao nível do mar até $700 \mathrm{kPa}$, e a temperatura oscila de $80^{\circ} \mathrm{C}$ $120^{\circ} \mathrm{C}$ e é controlada por trocadores de calor internos e externos. A reação é exotérmica com um calor de

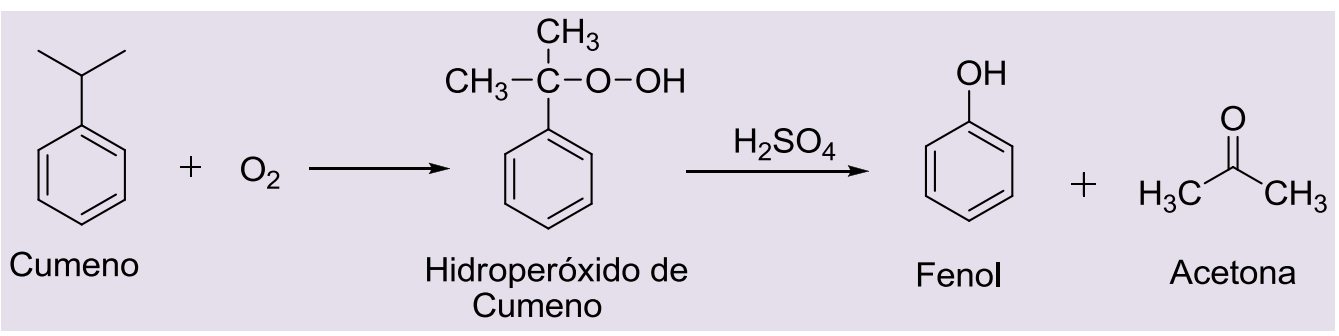

Esquema 3. Síntese de Hock para a obtenção do fenol 


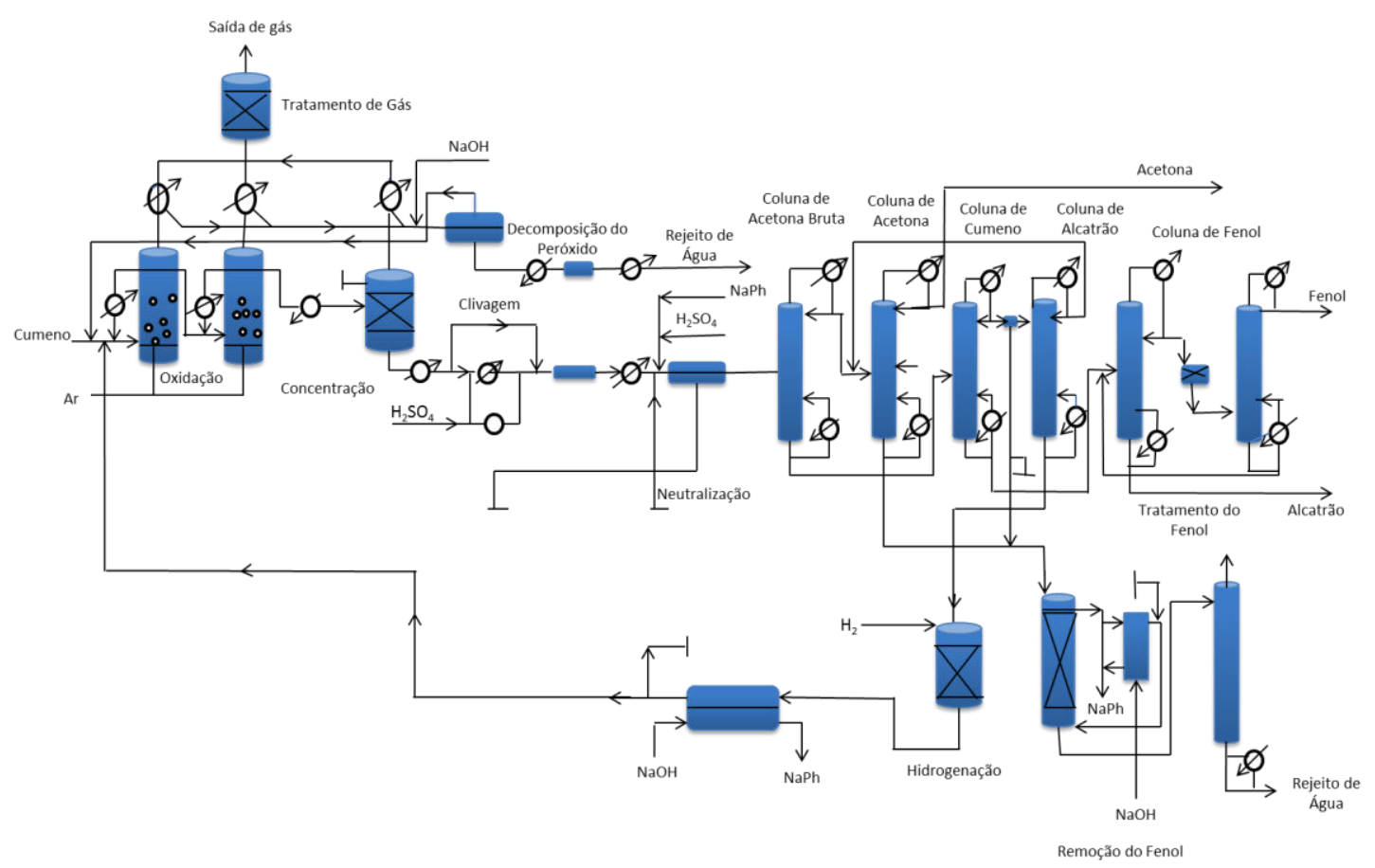

Esquema 4. Esquema de produção do fenol a partir do cumeno (adaptado da referência 11)

reação de $-117 \mathrm{~kJ} \cdot \mathrm{mol}^{-1} \cdot{ }^{11}$

Diversos subprodutos são formados na etapa de oxidação, a seletividade da reação é dependente da formação de álcool dimetilbenzílico(DMBA) e acetofenona (ACP). O DMBA é desidratado na unidade de clivagem levando a formação do $\alpha$-metilestireno (AMS). A acetofenona é removida do processo nas unidades de destilação e podem ser recuperadas como um produto puro. Outros subprodutos da oxidação são acido fórmico, ácido acético e pequenas quantidades de hidroperóxido de metila(MHP) que são removidas na liberação de gases. Como fenol é um grande inibidor da reação de oxidação, este deve ser removido no processo de reciclagem do cumeno.,

$\mathrm{Na}$ saída de gás dos reatores, são liberados

principalmente nitrogênio e outros compostos orgânicos, que são condensados a $0^{\circ} \mathrm{C} \mathrm{e}$ separados do cumeno. $\mathrm{O}$ gás liberado pode ser purificado sob pressão e pode ser utilizado na cobertura e ventilação de equipamentos e processos. A fase aquosa removida na saída de gás contém cumeno, sendo esta tratada com soda cáustica e o cumeno reciclado é levado para a unidade de oxidação. $^{11}$

$O$ produto da unidade de oxidação é concentrado a 6590\% em peso de CHP, isto se dá via uma destilação a vácuo em multi etapas na unidade de concentração. ${ }^{11}$
Na etapa seguinte tem-se a unidade de clivagem onde - hidroperóxido é decomposto a $50-60^{\circ} \mathrm{C}$, levando à formação de fenol via catálise em ácido sulfúrico.

Formam-se acetona e outros subprodutos que vão passar por condições especiais de tratamento nas unidades de destilação e assim separados dos produtos principais. ${ }^{11}$

O produto da unidade de clivagem é resfriado e fenolato de sódio é adicionado para a neutralização do ácido sulfúrico que então é removido sob a forma de sulfato de sódio. O produto de neutralização é enviado para a unidade de destilação, sendo a primeira delas a coluna de acetona, onde temos a obtenção de 
acetona pura como principal superior. A parte inferior da coluna da coluna de acetona é enviada para a primeira coluna de cumeno, onde este derivado assim como o AMS, fenol e agua são separados como produto superior. A agua é separada em um decantador e tratada para a remoção do fenol, acetona e cumeno e levada para a seção de tratamento. ${ }^{11}$

O cumeno é então separado na sua segunda coluna, o $\alpha$-metilestireno é hidrogenado nesta coluna levando a formação de mais cumeno (utilizando-se de paládio como catalisador seletivo), impedindo que haja qualquer alteração no fenol. Na fase aquosa, o cumeno é separado do fenóxido de sódio; este por sua vez é levado para uma unidade de neutralização. 0 cumeno é então reciclado para a unidade de oxidação..$^{5,11}$

O produtor inferior removido da coluna de cumeno é enviado para a coluna de alcatrão onde substâncias menos voláteis

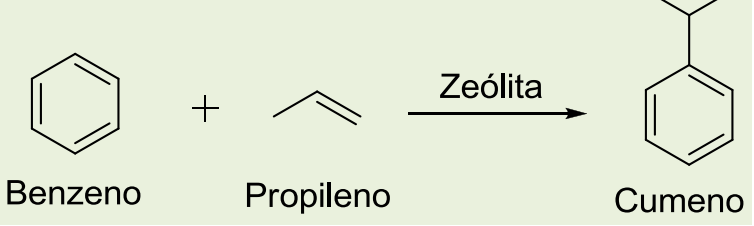

Esquema 5. Método de obtenção do cumeno via zeólita são removidas na parte de alta octanagem durante a

inferior, onde podem ser utilizadas como combustível para a produção de vapor. 0 fenol é então separado na parte superior da coluna e levado para uma etapa de tratamento para remoção de hidrocarbonetos residuais. $\mathrm{O}$ fenol puro é direcionado para a coluna de fenol onde é então removido na parte superior da coluna. ${ }^{5,11}$

\section{Produção do Cumeno}

O Cumeno é inicialmente produzido via alquilação do benzeno com propileno sob catálise ácida (Esquema 5). No Brasil, a principal empresa responsável pela produção do Cumeno é a Unipar. Ao longo dos anos muitos catalisadores já foram propostos para a reação de alquilação, como o trifluoreto de boro, fluoreto de hidrogênio, cloreto de alumínio e ácido fosfórico. 0 processo de produção do Cumeno foi desenvolvido entre 1939 e 1945 devido à demanda por combustíveis

\section{2}

Segunda Guerra Mundial. Atualmente o Cumeno não é mais usado como combustível, e a sua demanda se dá para a produção de fenol, acetona e $\alpha$-metilestireno. ${ }^{5,9,12}$

O início da produção do cumeno foi marcado pelo processo onde se empregava como catalisador o ácido fosfórico em fase sólida (Solid Phosphoric Acid, SPA). Embora este método ainda seja viável, ela possui limitações a serem consideradas. São elas:

- O rendimento limite é de $95 \%$ devido a oligomerização do propileno levando à formação de subprodutos alquilados de alto peso molecular. ${ }^{5,12}$

-É necessária uma alta razão de benzeno/propileno, na ordem de 7/1 para manter o alto rendimento;

- O catalisador não pode ser regenerado e deve ser descartado ao fim de cada ciclo.

Ao longo dos anos, melhorias no processo SPA permitiram manter o ritmo da demanda por cumeno, entretanto ainda havia a necessidade de se obter o produto com uma qualidade superior e maior rendimento. No final dos anos 80, processos baseados em 


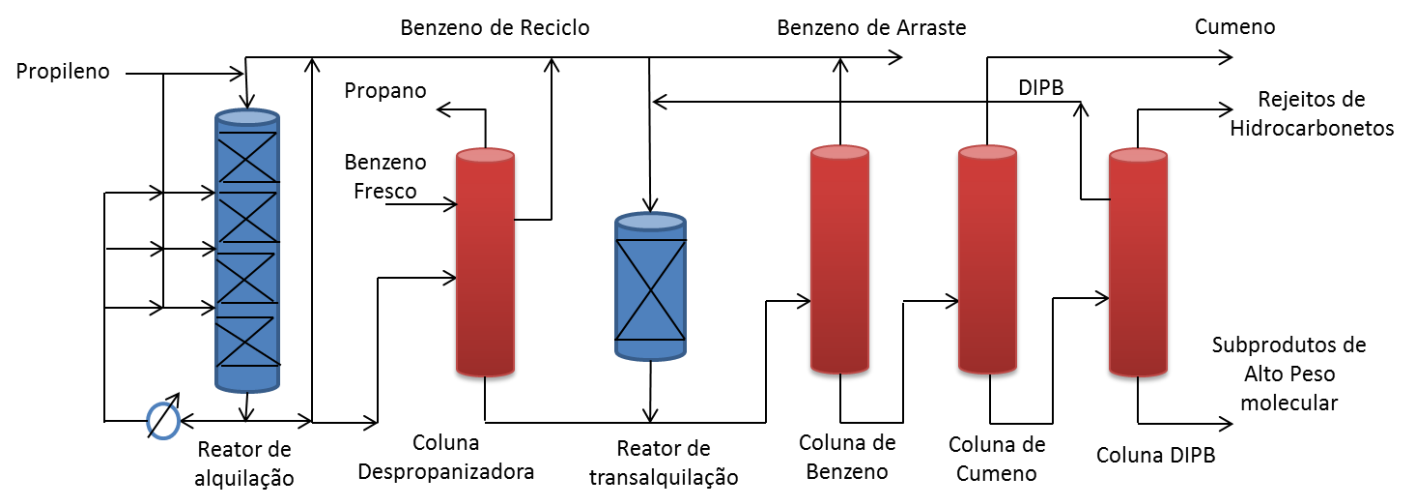

Esquema 6. Diagrama do processo Q-Max ${ }^{\mathrm{TM}}$ para a obtenção do cumeno.(adaptado da referência 5)

catálise via zeólitas foram desenvolvidas, e atualmente todo o cumeno é produzido utilizando-se este tipo de catálise, que é capaz de gerar o produto com $99 \%$ de rendimento. $^{5}$

O processo Q-Max ${ }^{\mathrm{TM}}$, baseado em zeólitas, é utilizado mundialmente, possui um baixo custo, maior rendimento, e o catalisador pode ser regenerado. ${ }^{5,10}$

O Esquema 6 apresenta a produção do cumeno. Primeiramente temos 0 reator de alquilação, que é dividido em quatro leitos catalíticos. A alimentação de benzeno fresco é encaminhada através da seção superior da coluna despropanizadora para remover excesso de água, em seguida é então enviado para o reator de alquilação através de uma corrente de reciclo. Já o benzeno reciclado nos reatores de alquilação e transalquilação é oriundo da coluna de benzeno. A mistura de benzeno fresco e reciclado é levado para o reator de alquilação onde é escoado para o seu preenchimento. ${ }^{5}$

A alimentação de propileno fresco é dividida entre os leitos catalíticos $\mathrm{e}$ completamente consumido em cada um deles. Um excesso de benzeno é utilizado para se evitar uma polialquilação e ajudar a minimizar a oligomerização da olefina. Como temos uma reação exotérmica, a temperatura do reator de alquilação pode ser controlada pela recirculação de uma fração do efluente deste mesmo reator, assim atuando como um dissipador de calor. Esse é um dos motivos pelo qual o reator foi dividido em quatro leitos, para garantir uma alta conversão, uma vez que a temperatura de entrada dos leitos é a mesma do primeiro leito. $^{5}$
O efluente do reator de alquilação é levado para a coluna de despropanização a qual remove o propano e excesso de água que podem ter entrado com a alimentação de propileno. 0 efluente desta coluna é direcionado para a coluna de benzeno, onde o excesso de benzeno é coletado e reciclado e a outra parte segue para a coluna de cumeno onde o produto final é recuperado. $O$ subproduto da coluna de cumeno é composto

predominantemente por diisopropilbenzeno (DIPB), que é levado para a coluna DIPB. Se a alimentação de propileno possuir excesso de buteno ou se a alimentação de benzeno possuir excesso de tolueno, butilbenzeno ou cimenos estes são destilados e removidos da coluna DIPB na parte superior, já o excesso de diisopropilbenzeno é levado para o reator de transalquilação para reciclagem. Subprodutos 
aromáticos de alto peso molecular são removidos da parte inferior da coluna. 0 DIPB reciclado da coluna é combinado com o benzeno reciclado e é levado ao reator de transalquilação onde é convertido em cumeno adicional. $\mathrm{O}$ efluente é então levado para a coluna de benzeno. ${ }^{5}$

\section{Aplicações do Fenol}

\section{Aplicações do Fenol na} Sintese de Materiais

O fenol é uma matéria prima de grande importância industrial. Suas principais aplicações são: fabricação de resinas fenólicas, do bisfenol A (BPA), um intermediário sintético para fabricação de resinas epóxi e policarbonato, que são de grande importância na produção de garrafas plásticas, mamadeiras, copos de plástico entre outros produtos, além de também ser utilizado na produção de caprolactama, um intermediário da produção do nylon (Esquema 7). 0 fenol também é utilizado como solvente e reagente químico em laboratório. ${ }^{12,13}$

Uma das maiores aplicações do fenol se dá na fabricação de resinas a base de fenol-formaldeído.

Resinas fenólicas possuem grande resistência térmica, a água e produtos químicos, também possuem boas propriedades dielétricas, uma superfície rígida e grande estabilidade dimensional. 0 custo de produção dessas resinas é relativamente baixo e podem ser formuladas para as necessidades das indústrias elétricas, automotiva, de equipamentos e adesivas. ${ }^{12,14}$

A indústria adesiva compreende o maior mercado de resinas fenólicas, com aplicações em colagem de madeira compensada e placas de partícula. Resinas fenólicas também são utilizadas na fabricação de laminados como Formica. Molduras fenólicas possuem uma coloração escura, são comumente utilizados em plugues elétricos e eram anteriormente usados para telefones. $^{12,14}$

Outras aplicações da resina incluem o uso de suas propriedades isolantes, abrasivas, e como material de fundição para moldes em casca. São utilizadas em lonas de freio, revestimentos de embreagem e outras peças de friç̧ão onde é necessário um aglutinante termoestável e resistente. ${ }^{12,14}$

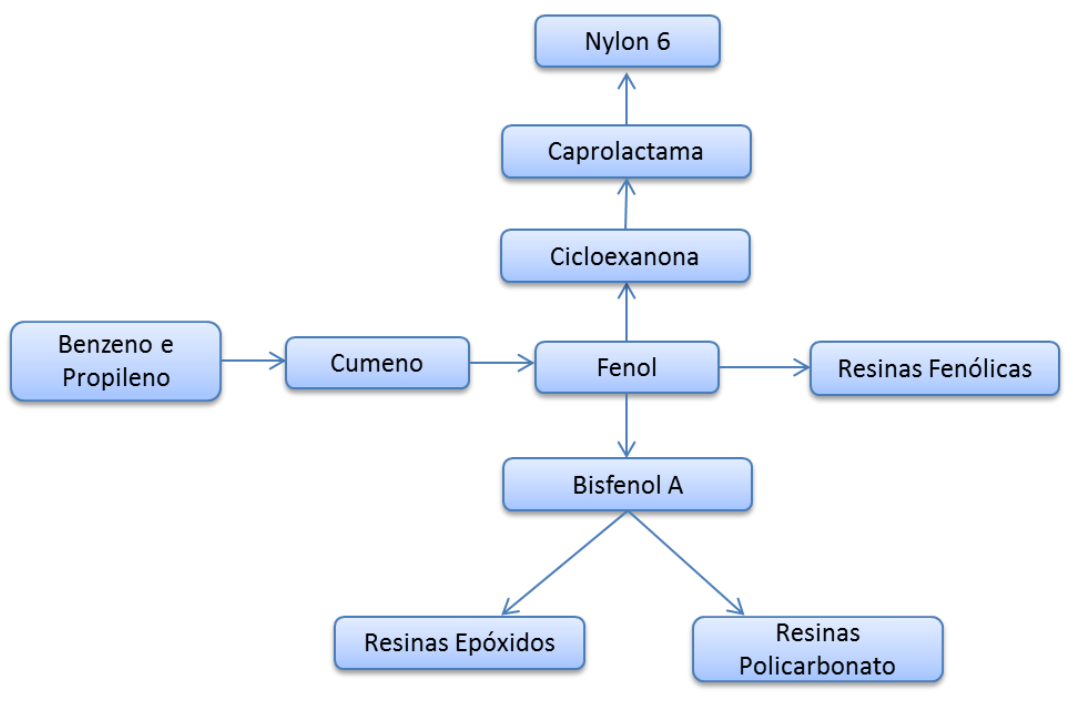

Esquema 7. Panorama dos produtos obtidos a partir do fenol 
As resinas fenólicas são produzidas pela reação química entre o fenol e o formaldeído, bem como seus derivados. As estruturas obtidas dependem de fatores como razão molar entre as espécies, do $\mathrm{pH}$ da reação, do catalisador empregado $\mathrm{e}$ da temperatura de reação. As resinas fenólicas podem ser divididas em dois grupos, que são as resinas do tipo Novolac e Resol. As propriedades químicas, físicas e mecânicas das resinas Novolac e Resol quando curadas, são praticamente as mesmas. A maior diferença está na estrutura molecular do prépolímero. A massa molecular do pré-polímero das resinas do tipo Resol possuem baixo peso molecular e necessitam de alta temperatura e até mesmo presença de ácido forte como agente de cura. Essas resinas possuem um menor teor de sólidos quando comparadas ao prépolímero da resina novolac que possui massa molar mais elevada e é curada mediante a um agente alcalino, geralmente

hexametiltetramino

(HMTA). ${ }^{11}$

Em processos industriais como a pultrusão (processo onde se produz materiais a base de polímeros reforçados com fibras de vidro), resinas do tipo resol se mostram instáveis e o processo acaba por diminuir a resistência mecânica frente às resinas novolac. ${ }^{11,15}$

As propriedades químicas do fenol são únicas, a presença do grupamento hidroxila no anel aromático facilita reações de substituição do tipo eletrofílica e nucleofílica. O anel aromático possui uma alta reatividade para substituição eletrofílica aromática (SEAr). Para a formação das resinas a substituição ocorre frente ao formaldeído sob catálise ácida. O fenol é um ácido fraco e em condição básica, forma-se fenóxido de sódio, que por sua vez reage com formaldeído via adição nucleofílica do anel aromático à carbonila. ${ }^{11,15}$

Esta capacidade única do fenol de reagir com formaldeído via catálise ácida ou básica leva a formação das diferentes resinas, novolac (catálise ácida) e resol (catálise básica) (Esquema 8$).{ }^{15}$

Quando uma resina resol é preparada utiliza-se uma quantidade equimolar ou uma maior quantidade de formaldeído sob catálise básica, já quando uma resina novolac é preparada utilizase uma quantidade de formaldeído abaixo da equimolar em relação ao fenol. ${ }^{15}$

Outra aplicação de grande importância do fenol é a sua utilização na produção de

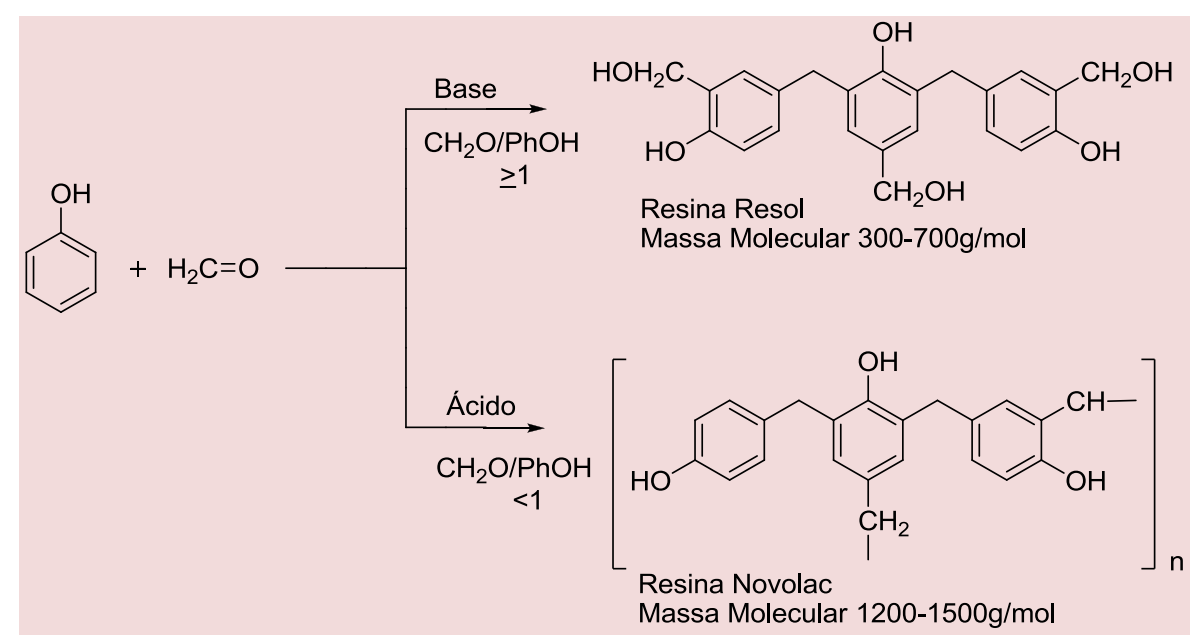

Esquema 8. Polimerização do Fenol e obtenção da resina Resol e Novolac 


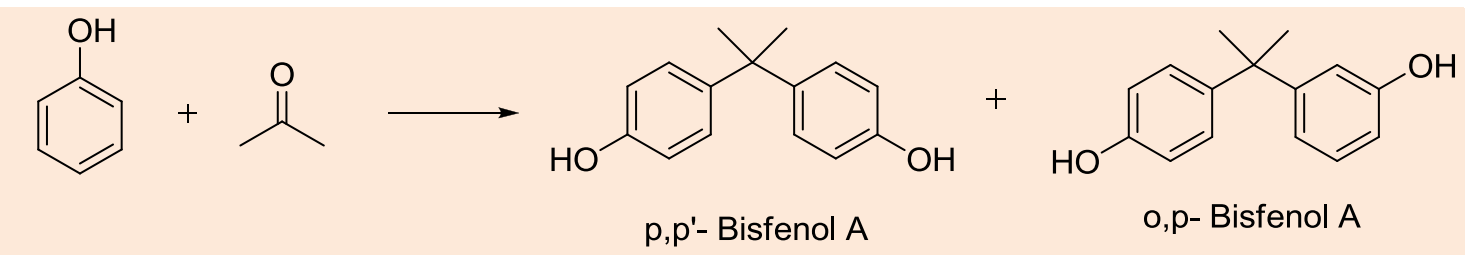

Esquema 9. Síntese dos isômeros de posição do Bisfenol A

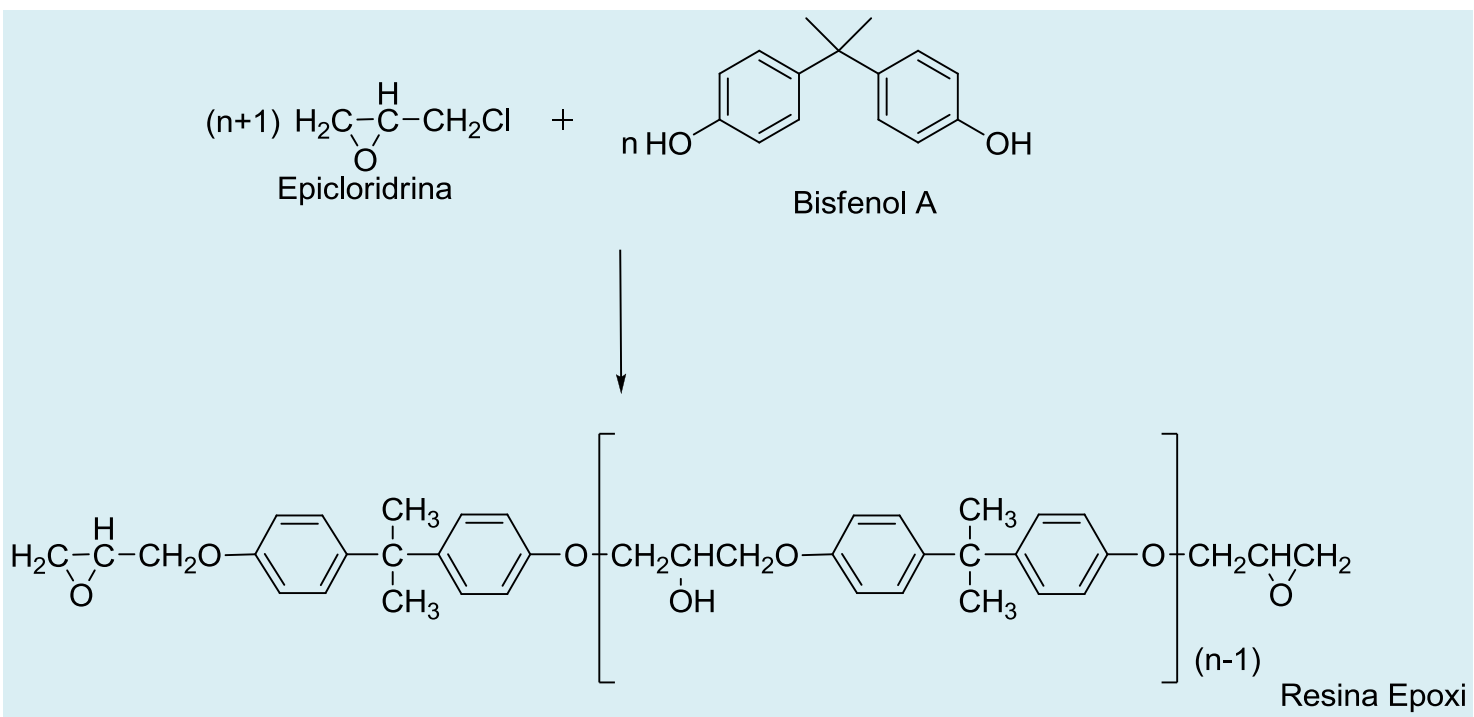

Esquema 10. Reação do Bisfenol A com Epicloridrina para a obtenção de resina Epóxi

bisfenol $A(B P A)$, um material de grande importância na produção de polímeros, sejam eles resinas epóxidos (quando reagem com epicloridrina) ou resinas de policarbonato(quando

reagem com fosgênio). O Bisfenol A foi sintetizado pela primeira vez pelo russo Alexander P. Dianin em 1891, e a sua obtenção se dá pela reação entre 2 mols de fenol e $1 \mathrm{~mol}$ de acetona, sendo possível obter o $p, p$-Bisfenol

A e $O \quad o, p$-Bisfenol A (Esquema 9). ${ }^{13,16}$

A separação dos isômeros se dá pela combinação entre destilação e cristalização. Em 2001 nos EUA 62\% do bisfenol $A$ era utilizado na produção de resinas de bisfenol-A com a policarbonato e $23 \%$ na epicloridrina. (Esquema 10) ${ }^{17}$ produção de resinas epóxidos, 2 \% eram utilizados na produção do tetrabromobisfenol A um agente usado na prevenção de incêndios e $13 \%$ para exportação e outros usos. ${ }^{12}$

As resinas epóxi passaram a ter importância comercial em 1947. O primeiro produto deste tipo foi fabricado pela Devoe-Raynolds Company. As propriedades adesivas, resistência química e dureza rapidamente se provaram úteis para a indústria de revestimento de superfícies. Essas resinas são obtidas por meio da condensação do

As resinas de policarbonato são oriundas 


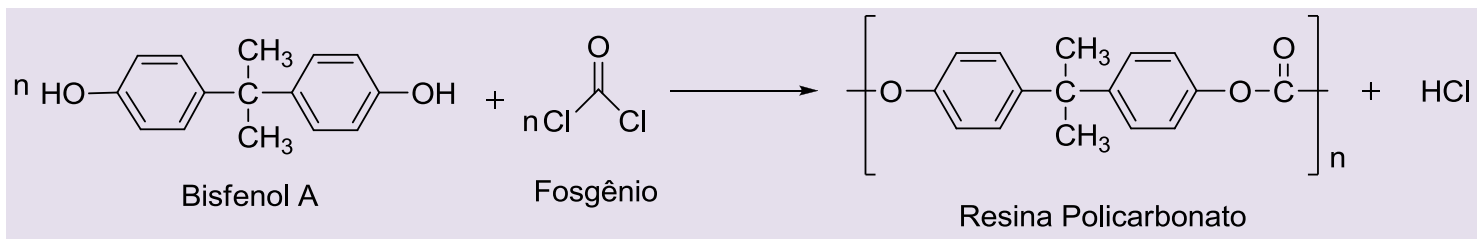

Esquema 11. Reação de polimerização para formação da resina Policarbonato

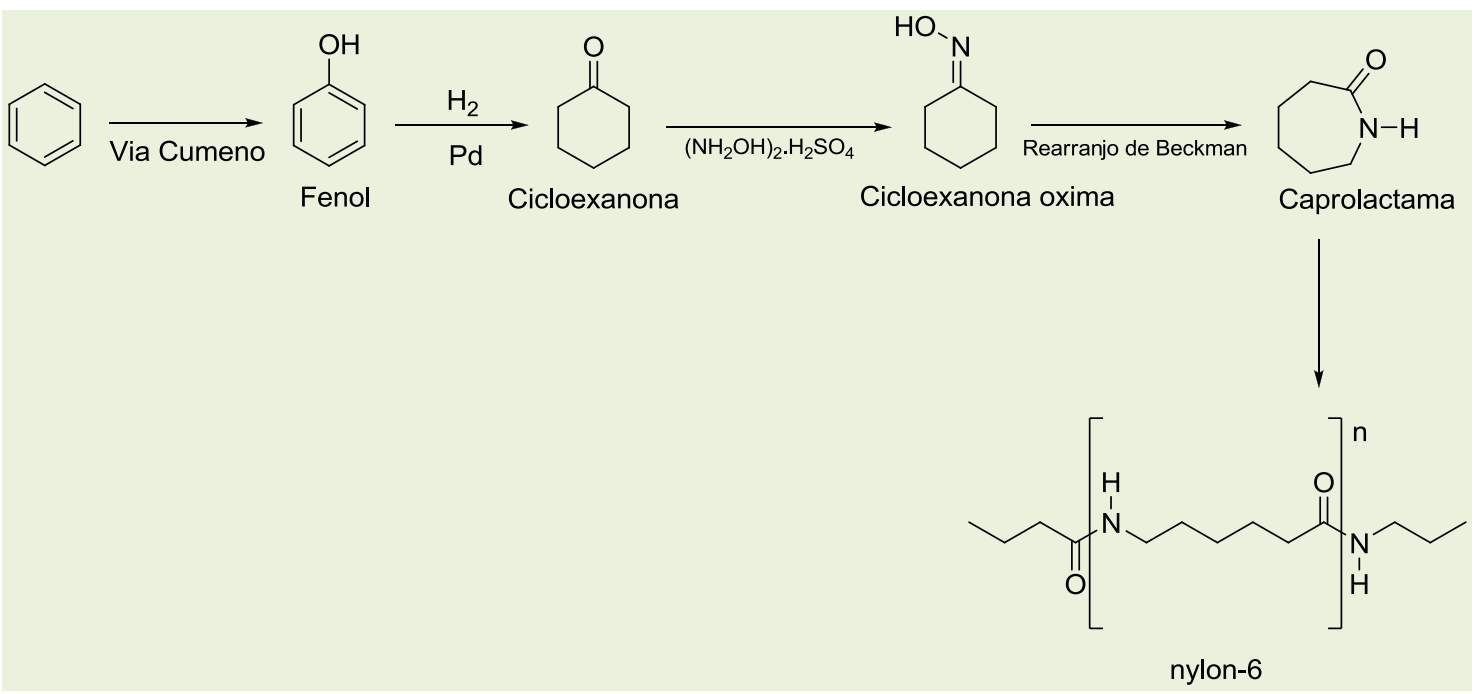

Esquema 12. Rota sintética de preparação do Nylon-6

do bisfenol $A$ e são obtidas pela condensação do mesmo com fosgênio (Esquema 11). São termoplásticos, com clareza excepcional, resistentes ao impacto, resistentes a chama e de baixo empenamento. $\mathrm{O}$ fosgênio é extremamente tóxico e foi utilizado como arma química durante a primeira guerra mundial. No inicio dos anos 90 a General Eletric construiu um sistema de produção de policarbonato no Japão a qual não utilizava fosgênio na via sintética, outras empresas como a Bayer e Asahi desenvolveram depois rotas similares. ${ }^{12,18}$
O fenol também é um intermediário fundamental na produção do Nylon 6, um dos muitos tipos de fibras sintéticas. ${ }^{19}$ O Nylon é uma poliamida e foi a primeira fibra sintética produzida, que despertou grande interesse comercial pelas suas propriedades. Possuem grande elasticidade e uma resistência a tração maior do que lã, seda, raiom e algodão. Outra característica importante é a sua estabilidade química, são resistentes a álcalis, gorduras vegetais e peróxidos. Entretanto sua resistência a ácidos minerais é baixa. Devido a suas propriedades possuem uma gama de aplicações, encontradas em tapetes, roupas, bagagens, peças para automóveis, escovas industrias entre outros. ${ }^{20}$

O nylon surgiu da pesquisa em polímeros conduzida pelo Dr. Wallace Carothers no início da década de 30 no setor de pesquisa da empresa Norte Americana DuPont, tendo a sua produção comercial iniciado em $1939 .^{20}$

Há uma grande variedade de fibras de nylon no mercado, sendo estas, diferenciadas pela estrutura molecular do polímero. 0 Nylon 6 é uma poliamida gerada a partir da caprolactama, um 
intermediário oriundo do fenol. A produção deste intermediário denota o terceiro maior uso de fenol nos EUA, sendo a Honeywell a maior produtora de Nylon 6 na américa do norte e no mundo. Para se produzir a caprolactama, o fenol é submetido a reação de hidrogenação catalítica fornecendo a cicloexanona, seguido da reação com sulfato de hidroxilamina, formando uma oxima que sofre um rearranjo levando à síntese da caprolactama. ${ }^{20,21}$

A caprolactama obtida é a matéria prima utilizada nas reações de polimerização que levam a formação do nylon 6 (Esquema 12). ${ }^{22}$

\section{Aplicações do Fenol em}

\section{Síntese Orgânica}

As reações químicas em que 0 fenol pode ser empregado constituem um grande campo na síntese orgânica. Um exemplo característico se dá nas reações de substituição eletrofílica aromática, em que a hidroxila atua como<smiles>O=[N+]([O-])c1ccc(O)c([N+](=O)[O-])c1</smiles>

Esquema 13. Esquema de nitração do fenol<smiles>CC(=O)Oc1cc(N=N)ccc1C(=O)ON=C(Cl)C(Cl)N=Nc1ccc(N)cc1C(=O)O</smiles>

$\ominus$<smiles>CC(=O)Oc1cc([N+]#N)ccc1C(=O)O</smiles><smiles>O=[N+]([O-])c1ccccc1O</smiles><smiles>COc1cc(N=Nc2ccc(O)c([N+](=O)[O-])c2)ccc1C(=O)O</smiles>

Esquema 14. Reação de formação de azo-fenol<smiles>Cc1cccc(O)c1CCc1cc(O)ccc1O</smiles>

Esquema 15. Oxidação do fenol por oxigênio molecular em meio aquoso 
um forte ativante do anel aromático, levando a produtos de substituição majoritários com orientação nas posições orto e para. Tal propriedade demonstra a importância sintética desta matéria prima. ${ }^{23}$

Fenóis também participam de reações de oxidação e diversas reações relacionadas exclusivamente ao grupamento hidroxila, como na preparação de aril éteres pelo método de Williamson ou preparação de ésteres via acetilação da hidroxila. $^{24}$

A nitração do fenol é uma reação de grande importância industrial. Os produtos gerados possuem usos como precursores para a obtenção de corantes, fármacos, agrotóxicos entre outros. $^{25}$

Tradicionalmente, a reação de nitração se dá pela mistura de ácido nítrico e ácido sulfúrico (mistura sulfonítrica). $\mathrm{O}$ ácido sulfúrico atua protonando o ácido nítrico de forma a gerar maior quantidade do eletrófilo livre para a reação (íon nitrônio). O eletrófilo então pode sofrer o ataque do par de elétrons do anel aromático levando à formação de um intermediário chamado complexo $\sigma$, em que há uma carga positiva deslocalizada no anel. A etapa seguinte é de abstração do hidrogênio por uma base, restabelecendo a aromaticidade do sistema. ${ }^{23}$

O efeito do substituinte em reações de substituição eletrofílica aromática é muito importante uma vez que governa a velocidade da reação bem como a sua regiosseletividade. No caso do fenol, temos a hidroxila que é capaz de estabilizar a carga positiva do complexo $\sigma$ nas posições orto e para, favorecendo tais posições para a SEAr. A força do eletrófilo também é levada em consideração quanto à regiosseletividade, eletrófilos mais reativos apresentam menor seletividade posicional e vice versa. ${ }^{23}$

A nitração do fenol pela metodologia clássica é eficaz, entretanto pouco seletiva, devido a isso há inúmeras metodologias descritas relatando aumento de regioseletividade: catálise via zeólitas, ativação por microondas, uso de ácido nítrico diluído sob catalisadores de transferência de fase entre outros. $^{26,27}$

Nitrofenóis podem ser utilizados na síntese de diversos azo compostos. Esses derivados são obtidos por meio da reação entre

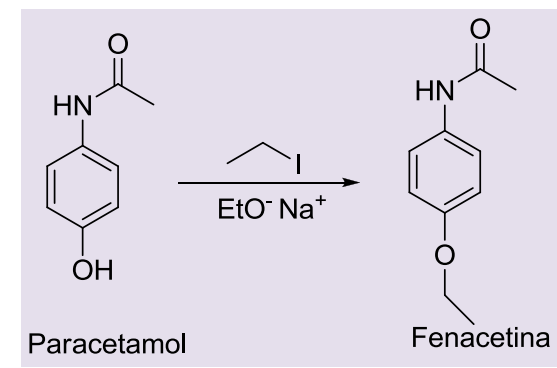

Esquema 16. Síntese de Williamson para a formação de aril éteres

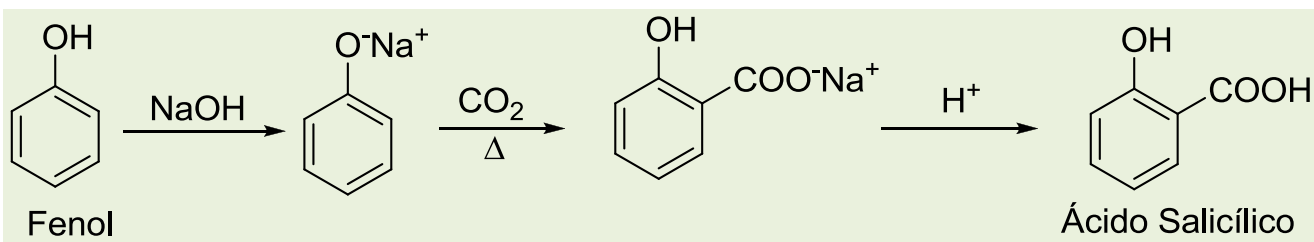

Esquema 17. Síntese de Kolbe-Smittt para a formação do Ácido Salicílico 
<smiles>CC(=O)OC(C)=O</smiles>

Ácido Salicílico<smiles>CC(=O)Oc1ccccc1C(=O)O</smiles>

Ácido acetilsalicílico

Esquema 18. Reação de O-Acilação para a formação do Ácido Acetilsalicílico<smiles>CC(=O)OC(C)=O</smiles>

Esquema 19. Reação de acilação de Friedel Crafts no fenol

uma anilina em meio ácido, na presença de nitrito de sódio frente a um anel suficientemente ativado para uma reação de substituição eletrofílica aromática

(Esquema 14). ${ }^{27}$

Como não há um hidrogênio $\alpha$ ligado ao carbono da hidroxila, fenóis poderiam ser comparados a álcoois terciários e não sofrer reações de oxidação. Entretanto isso não acontece. Fenóis são oxidados a outras espécies como o catecol e hidroquinona, que também podem sofrer reações de oxidações consecutivas levando a outras espécies, como as quinonas (Esquema 15)..$^{24}$

A oxidação em meio aquoso do fenol e compostos fenólicos é de grande interesse industrial por ser uma medida de descontaminação de águas residuais de refinarias, petroquímicas e carvão processado, por levar formação de moléculas orgânicas de cadeia curta e $\mathrm{CO}_{2}{ }^{29}$

A síntese de Williamson é uma alternativa sintética para a obtenção de éteres, e no caso do fenol aril éteres. A reação se dá pela desprotonação da hidroxila fenólica por uma base para então termos o fenóxido como nucleófilo de uma reação SN2 com um brometo de alquila. Essa metodologia era empregada na preparação da fenacetina, um analgésico e antipirético cuja a comercialização foi proibida pelo FDA em 1983 (Esquema 16). ${ }^{24,30}$

\section{Ácidos}

carboxílicos

\section{aromáticos} são intermediários importantes na síntese de diversos produtos como fármacos, agentes antissépticos, fungicidas, corantes poliésteres entre outros. A forma mais convencional para a preparação destas substâncias foi descrita em 1860 por Kolbe-Schmitt, também conhecido por ter desenvolvido o método de preparação do ácido salicílico, o intermediário sintético do ácido acetilsalicílico, principio ativo da Aspirina. A metodologia se dá pela adição de $\mathrm{CO}_{2}$ a alta temperatura e pressão à mistura de fenol e hidróxido de sódio. O produto final é então acidificado levando à formação do acido salicílico (Esquema 17). ${ }^{31,32}$

Para a obtenção do ácido acetilsalićlico a reação de acilação da hidroxila sob catálise ácida é a metodologia mais comumente empregada (Esquema 18). A acilação do anel aromático, também conhecido como acilação de Friedel Crafts é de grande importância sintética e se diferencia da O-acilação pelo 
emprego de um ácido de Lewis como catalisador como por exemplo $0 \quad \mathrm{AlCl}_{3}$ (Esquema 19). ${ }^{24,33}$

\section{Toxicidade}

O fenol é tóxico para seres humanos e animais, e é um contaminante de risco para o meio ambiente. São contaminantes oriundos de industriais químicas, farmacêuticas de tintas e de petróleo. O fenol e seus derivados são um risco para o homem e animais, pois ao penetrarem na célula são metabolizados e levam à formação de radicais livres e metabólitos eletrofílicos que podem se ligar ao DNA. ${ }^{34}$

O fenol também é um irritante dérmico, capaz de causar necrose não só na pele, mas em células de outros tecidos como rins, fígado, músculo e olhos. 0 dano tecidual no nível de epiderme, se dá pela reação do fenol com aminoácidos contidos na queratina. $A$ quantidade de $1 \mathrm{~g}$ de fenol pode ser letal para um homem adulto, entretanto esse valor pode variar de pessoa para pessoa. 0 envenenamento por fenol leva a sintomas como boca e garganta seca, urina escura e grande irritação nas mucosas. A exposição crônica aos vapores de fenol pode causar: perda de peso, anorexia, fraqueza, cefaleia e dores musculares além de danos teciduais no fígado, rins, e pulmão. ${ }^{34,35}$

Muitos epidemiologistas já estudaram o possível efeito carcinógeno do fenol, entretanto não foi encontrada uma relação dose-resposta. Com as informações até então encontradas não é possível classificá-lo como um carcinógeno humano. ${ }^{35}$

O Bisfenol A, um importante derivado do fenol é produzido e comercializado em escala global, apresenta uma elevada toxicidade e se mostra um risco para o meio ambiente. O BPA é considerado um xenoestrogênio, capaz de perturbar funções endócrinas por mimetizar ou bloquear a função de hormônios endógenos. Os efeitos endócrinos se dão em hormônios sexuais, leptina, tiroxina, insulina, entre outros. O BPA é capaz de gerar espécies livres de oxigênio, sendo tóxico também por estresse oxidativo, é hepatotóxico, imunotóxico e mutagênico. ${ }^{36}$

Devido à sua comprovada toxicidade, muitos países decidiram banir a produção de garrafas e embalagens feitas de resinas epóxi e policarbonatos, devido à contaminação de alimentos e da água pelo bisfenol A. Uma substituição pelo bisfenol $S$ ou outros polímeros análogos vem sendo conduzida em muitos países, entretanto a toxicidade destes substitutos ainda é questionável, sendo necessário um maior estudo para entender o seu possível impacto ambiental e danos em seres vivos. ${ }^{36}$

\section{Referências bibliográficas}

${ }^{1}$ O'Neil, M. J.; Merck Index, 14a. ed., Merck: Whitehouse Station, 2006;

${ }^{2}$ Tyman, J. H. P.; Studies in Organic Chemistry 52, Synthetic And Natural Phenols, 1a. ed., Elsevier: Amsterdam, 1996.

${ }^{3}$ Costa, P. R. R.; Ferreira, V. F.; Esteves, P. M.; Vasconcellos, M. L. A. A.; Ácidos e Bases em Química Orgânica, Editora Bookman: Porto Alegre, 2005.

4 Thomson, R. H. Phenol Tautomerism. Quartely Reviews Chemical Society 1956, 10, 27. [CrossRef]

5 Schmidt, R. J. Industrial catalytic processes-phenol production. Applied Catalysis A: General 2005, 280, 89. [CrossRef]

6 Barcza, M. V. Apostila de Processos Unitários Orgânicos. Disponível em: 
$<$ http://www.dequi.eel.usp.b r/\%257Ebarcza/Oxidacao.pdf >. Acesso em: 24 junho 2014.

7 Rhodia Solvey Group no Brasil. Disponível em: $<$ http://www.rhodia.com.br/ pt/about us/rhodia in brazi //index.tcm >. Acesso em : 27 março 2015.

8 INEOS fact files 2010. Disponível em: $<$ http://www.ineos.com/Doc uments/Fact-

Files/INE FF 200901 web. pdf>. Acesso em: 27 março 2015.

9 Unipar Relatório da administração 2008 . Disponível em: <http://www.uniparcarboclo ro.com.br/uniparcarbocloro/ web/arquivos/UNIPAR RAD M 2008 port.pdf $>$. Acesso em: 9 agosto 2014 .

10 Process Technology and Equiment, Q-MAX ${ }^{\mathrm{TM}}$ Process. Disponível em: $<$ http://www.dequi.eel.usp.b r/ barcza/CumenoUOP.pdf $>$. Acesso em: 9 agosto 2014.

${ }^{11}$ Pilato; Phenolic Resisns: A Century of Progress, 1a. ed., Springer: New York, 2010.

${ }^{12}$ Wittcoff, H. A, Reuben, B. G, Plotkin, J. S.; Industrial Organic Chemicals, 2a ed., Wiley-Intercience: New Jersey, 2004.

${ }^{13}$ Huang, Y. Q.; Wong, C. K. C.; Zheng, J. S.; Bouwman, H.; Barra, R.; Wahsltröm, B.; Neretin, L.; Wong, M. H. Bisphenol $A$ (BPA) in China: $A$ review of sources, environmental levels, and potential human health impacts. Enviromental International 2012, 42, 91. [CrossRef] [PubMed]

14 Haupt, R. A.; Jr, T. S. Characterizations of PhenolFormaldehyde Resol Resins. Industrial \& Engineering Chemistry Research 1994, 33, 693. [CrossRef]

${ }^{15}$ Borges, S. G.; Dissertação de Mestrado, Universidade Federal do Rio Grande do Sul, 2004. [Link]

${ }^{16}$ Das, D.; Lee, J. F.; Cheng.S. Selective synthesis of Bisphenol-A over mesoporous MCM silica catalysts functionalized with sulfonic acid groups. Journal of Catalysis 2004, 223, 152. [CrossRef]

${ }^{17}$ May, C. A.; Epoxy Resins, Chemistry and Technology, 2a. ed, Marcel Dekker: New York, 1988.

${ }^{18}$ Jing, B.; Dai, W.; Chen, S.; Hu, T.; Liu, P. Mechanical behavior and fracture toughness evaluation of $\mathrm{K}$ resin grafted with maleic anhydride compatibilized polycarbonate/K resin blends. Materials Science and Engineering A 2007, 444, 84. [CrossRef]

19 Thomas, J. M.; Raja, R. Design of a "green" one-step catalytic production of $\varepsilon$ caprolactam (precursor of nylon-6). Proceedings of the National Academy of Sciences 2005, 102, 13732. [CrossRef] [PubMed]

20 Bolton, E. K. Chemical Industry Medal. Development of Nylon.
Industrial and Engineering Chemistry 1942, 34, 53. [CrossRef]

21 Broomall, P. A. A Brief Overview of the Nylon 6 Market in North America. Disponível em: <http://www.polymerplace.c om/articles/update\%20nylon 6.pdf $>$. Acesso em: 12 setembro 2014.

${ }^{22}$ Meuldijk, J.; van de Kruijs, B. H. P.; van Vekemans, J. A. J. M.; Hulshof, L. A.; Duchateau, R.; Koning, C. E. A Novel Production Route for Nylon-6: Aspects of Microwave-Enhanced

Catalysis. Macromolecular Symposia 2011, 302, 69. [CrossRef]

${ }^{23}$ Carey, F. A.; Sundberg, R. J.; Advanced Organic Chemistry, Part A: Structure and Mechanism, 4a. ed., Springer Science + Business Media, LLC: New York, 2000.

24 Bruice, P. Y.; Organic Chemistry, 4a. ed., Prentice Hall: Santa Barbara, 2004.

${ }^{25}$ Desmurs, J.; Ratton, S.; The Roots of Organic Development, Volume 8, 1a ed., Elsevier: Amsterdam, 1996.

${ }^{26}$ Sunajadev, R. S.; Sugunan, $S$. Selective nitration of phenol over sulfated titania systems prepared via sol-gel route. Material Letters 2006, 60, 3813. [CrossRef]

${ }^{27}$ Joshi, A. V.; Baidoosi, M.; Mukhopadhyay, S.; Sasson, Y. Nitration of Phenol and Substituted Phenols with Dilute Nitric Acid Using 
Phase-Transfer Catalysts. Organic Process Research \& Development 2003, 7, 95. [CrossRef]

${ }^{28}$ Sheng, F. S.; Zheng, H. X.; Liu, J.; Zhao, Z. B. Synthesis of phenol-class azo derivatives of 4aminosalicylic acid. Chinese Chemical Letters 2008, 19, 419. [CrossRef]

29 Devilln, H. R.; Harris, I. Mechanism of the oxidation of aqueous phenol with dissolved oxygen. Industrial \& Engineering Chemistry Fundamentals 1984, 23, 387. [CrossRef]

30 Baptistella, L. H. B.; Giacomini, R. A.; Imamura, P. M. Síntese dos analgésicos paracetamol e fenacetina e do adoçante dulcina: um projeto para química orgânica experimental. Química Nova 2003, 26, 284.

[CrossRef]

${ }^{31}$ Stanescu, I.; Achenie, L. E. K. A theoretical study of solvent effects on KolbeSchmitt reaction kinetics. Chemical Engineering Science 2006, 61, 6199. [CrossRef]

32 Lijima, T.; Yamaguchi, T. Efficient regioselective carboxylation of phenol to salicylic acid with supercritical $\mathrm{CO}_{2}$ in the presence of aluminium bromide. Journal of Molecular Catalysis A: Chemical 2008, 295, 52. [CrossRef]

33 Tyagi, B.; Mishra, K. M.; Jasra, V. R. Solvent free synthesis of acetyl salicylic acid over nano-crystalline sulfated zirconia solid acid catalyst. Journal of Molecular Catalysis A: Chemical 2010, 317, 41. [CrossRef]

34 Michalowicz, J.; Duda, D. Phenols - Sources and Toxicity. Polish Journal of Environmental Studies 2007, 16, 347. [Link]

35 Toxicology Review of Phenol; U.S Environmental Protection Agency, Washington DC, 2002. Disponível em: <http://www.epa.gov/iris/to xreviews/0088tr.pdf>.

Acesso em: 21 outubro 2014.

${ }^{36}$ Michalowicz, J. Bisphenol A - Sources, toxicity and biotransformation.

Environmental Toxicology and Pharmacology 2014, 37, 738. [CrossRef]

\title{
Phenol (CAS 108-95-2)
}

\begin{abstract}
Phenol is a compound of industrial interest and in organic synthesis. It has a wide application in the materials industry being used in the production of phenolic resins, nylon and bisphenol A based resins. This paper shows the industrial synthesis of phenol and their reactions as well as physical-chemical properties, applications, toxicity among others.

Keywords: Phenol; industrial synthesis; resin; nylon; bisphenol A.

Resumo: O fenol é um composto de interesse industrial e em síntese orgânica. Possui uma grande aplicação na indústria de materiais sendo utilizado na produção de resinas fenólicas, nylon e resinas a base de bisfenol A. Este artigo apresenta a síntese industrial do fenol e suas reações, propriedades físico-químicas, aplicações, toxicidade entre outros.

palavras-chave: Fenol; síntese industrial; aplicações industriais; resinas; nylon; bisfenol A.

DOI: 10.5935/1984-6835.20150087
\end{abstract}

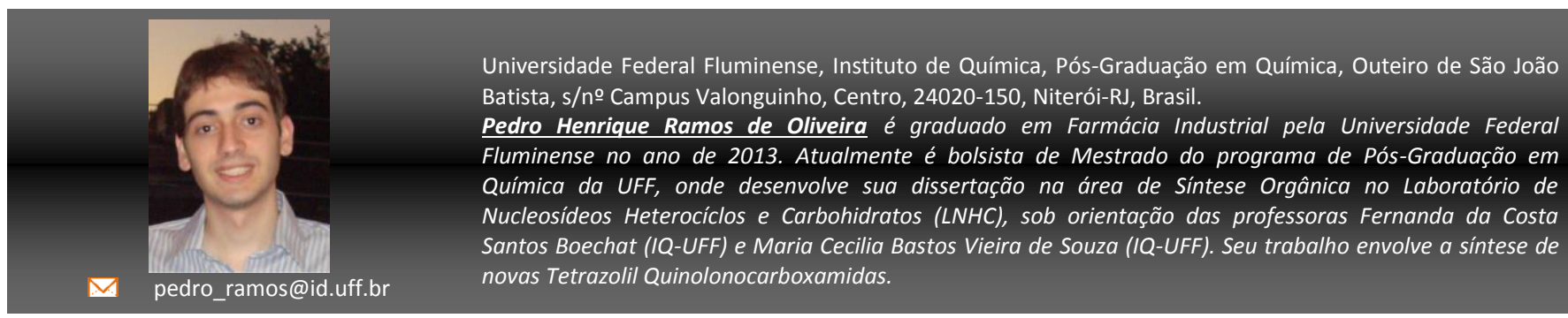

